\title{
Catalisadores ácidos baseados na simples modificação da quitosana para a esterificação do ácido oleico
}

\section{Acid catalysts based on simple modification of chitosan for the esterification of oleic acid}

\author{
Juliana Oliveira Cidreira ${ }^{1}$, Roberta Rocha Macêdo ${ }^{2}$, \\ Fernando Cesário Rangel ${ }^{1,2}$, Rosenira Serpa da Cruz ${ }^{1,2}$
}

\author{
${ }^{1}$ Programa de Pós-Graduação em Ciência, Inovação e Modelagem de Materiais, Departamento de Ciências Exatas e Tec- \\ nológicas - Universidade Estadual de Santa Cruz - Rodovia Jorge Amado, Km 16 - Ilhéus , CEP: 45662-900 Ilhéus, \\ Bahia, Brasil \\ ${ }^{2}$ Grupo Bioenergia e Meio Ambiente, BIOMA- Departamento de Ciências Exatas e Tecnológicas - Universidade Esta- \\ dual de Santa Cruz - Rodovia Jorge Amado, Km 16 - Ilhéus , CEP: 45662-900, Ilhéus, Bahia, Brasil \\ e-mail: julicidreira@gmail.com, beh_rocha16@hotmail.com,fcrangel@uesc.br, roserpa@uesc.br
}

\section{RESUMO}

A quitosana é um polímero linear com excelentes propriedades físico-químicas e tem sido amplamente utilizada em uma variedade de aplicações, incluindo como catalisador em vários tipos de reações. Neste trabalho, a quitosana comercial foi modificada, de modo a obter um material ativo e estável para ser utilizado como catalisador em reações de esterificação. Para este fim, a quitosana foi submetida à hidrólise ácida usando soluções de $\mathrm{HCl}$ ou $\mathrm{H}_{2} \mathrm{SO}_{4}$. A quitosana ácida foi então, caracterizada e avaliada na reação de esterificação do ácido oleico com metanol. Embora, a modificação da quitosana com soluções diluídas de ácidos inorgânicos seja um método simples para a preparação de catalisador heterogêneo ácido, há evidências que os materiais, apesar de apresentarem bons resultados de conversão do ácido oleico, não são estáveis frente à lixiviação das espécies ativa para o meio reacional nas condições avaliadas.

Palavras-chave: biodiesel, esterificação, acidez, lixiviação, reutilização.

\begin{abstract}
Chitosan is a linear polymer with excellent physicochemical properties and has been widely used in a variety of applications, including as a catalyst in various types of reactions. In this work, chitosan-based solids were synthesized in order to obtain an active and stable material to be used as a catalyst in esterification reactions. To this end, the chitosan was modified in order to potentiate its Bronsted acidity by acid hydrolysis using $\mathrm{HCl}$ or $\mathrm{H}_{2} \mathrm{SO}_{4}$ solutions and subsequent drying in a vacuum line. The synthesized materials were characterized and evaluated in the esterification reaction of oleic acid with methanol. Although modification of chitosan with dilute solutions of inorganic acids is a simple method for the preparation of heterogeneous acid catalyst, there is evidence that the materials are not stable against the leaching of the active species into the reaction medium under the conditions evaluated.
\end{abstract}

Keywords: biodiesel, esterification, acidity, leaching, reuse.

\section{INTRODUÇÃO}

A busca por processos industriais mais limpos vem ganhando importância e sendo objeto de estudo em diversas áreas da ciência. Nesse sentido, o emprego da biomassa é uma das alternativas que contempla os objetivos da química verde, pois apresenta baixo custo, alta disponibilidade, caráter renovável e múltiplas aplicabilidades [1,2].

A quitina, que constitui o exoesqueleto de crustáceos, insetos, moluscos e fungos, é a segunda maior fonte de biomassa renovável, ficando atrás apenas da celulose, portanto, considera-se que este polissacarídeo apresenta boas perspectivas para o desenvolvimento de novos derivados químicos e produtos de alto valor 
agregado [3-4].

Um dos derivados da quitina que tem ganhado destaque é a quitosana, um copolímero funcional, linear e biodegradável, obtido através do procedimento de desacetilação parcial da quitina [5-7]. A presença de grupos amino livres confere à quitosana propriedades tais como bifuncionalidade, solubilidade em soluções ácidas e possibilidade de modificação química estrutural [8-9]. Além dessas características a quitosana ainda apresenta excelentes propriedades como: não toxicidade, biocompatibilidade, biodegradação, reatividade e capacidade de adsorção. Estudos envolvendo a modificação estrutural da quitosana e seus derivados têm sido amplamente realizados com o intuito de empregar esses materiais em uma gama de aplicações [10-13], com destaque na área de catálise [8,14-16].

Tendo em vista a importância da produção do biodiesel num cenário de demanda energética nacional e mundial, pesquisas vêm sendo realizadas com o intuito de desenvolver materiais que atuem como catalisadores na produção deste biocombustível. O biodiesel pode ser obtido, através de diferentes processos com destaque para a transesterificação de triacilgliceróis e a esterificação de ácidos graxos [17]. Essa última é caracterizada por utilizar uma fonte de ácido graxo e um álcool de cadeia curta (geralmente metanol) em presença de um catalisador ácido e pode ser empregada tanto de forma isolada, ou como uma etapa associada à transesterificação ou à hidrólise.

Materiais que possuem propriedades ácidas de Bronsted apresentam boa atividade na esterificação de ácidos graxos. A princípio, catalisadores homogêneos como $\mathrm{H}_{2} \mathrm{SO}_{4}$ são os mais utilizados. No entanto, o emprego dessas espécies gera alguns inconvenientes, como a corrosão dos equipamentos além de exigir a sua separação do produto desejado afetando diretamente a qualidade do produto final [18].

Uma das alternativas utilizadas é a busca por catalisadores heterogêneos, visando à redução de operações unitárias envolvidas na separação e purificação dos produtos. No entanto, esses catalisadores ainda não são tão eficientes quanto os catalisadores homogêneos. Assim, um dos desafios tecnológicos da indústria de biodiesel é a busca por materiais heterogêneos eficientes que sejam capazes de garantir menor custo no processo, uso de condições mais brandas de temperatura e pressão, e apresentem viabilidade na sua recuperação [19-21].

Dentro destas premissas, a literatura mostra que diversos autores avaliaram a quitosana como catalisador ou como suporte para a produção de biodiesel, seja na transesterificação [8,14-16,22-24] ou esterificação [25-30] apresentando conversões e estabilidades satisfatórias. Caetano et al.[26] avaliarama a quitosana modificada com ácido sulfossuccínico (acidez de Bronsted de 2,04 $\mathrm{mmolH}^{+} \mathrm{g}^{-1}$ ) na esterificação do ácido palmítico com metanol a $60^{\circ} \mathrm{C}$ por $6 \mathrm{~h}$ e encontrou a convesão de $89 \%$. Já para o ácido oleico a conversão nas mesmas condições foi cerca de $34 \%$ menor. Vale ressaltar que o material não apresentou lixiviação e pôde ser reutilizado por 4 ciclos consecutivos sendo que uma uma ligeira queda de atividade do primeiro para o segundo ciclo e depois houve uma estabilização.

Bonazza et al.[27] investigaram diferentes estratégias imobilização da lipase Thermomyces lanuginosus (TLL) sobre a quitosana para atuar como catalisador na esterificação do ácido oleico. O melhor material apresentou conversão do ácido oleico em éster maior de $90 \%$ com $12 \mathrm{~h}$ de reação a $37^{\circ} \mathrm{C}$, apresentando uma perda de $18 \%$ de conversão após 5 ciclos de utilização. Tong et al.[28] sintetizaram materiais com tripla funcionalidade $\left(\mathrm{H}_{3} \mathrm{PW}_{12} \mathrm{O}_{40}, \mathrm{Ti}^{4+}\right.$ e quitosana) para atuar como catalisadores na esterificação do ácido palmítico. O material HPW $(29 \% \mathrm{~m} / \mathrm{m}) / \mathrm{Ti} /$ quitosana apresentou uma conversão do ácido palmítico em éster de 97,3\%. A alta conversão foi atribuída aos sítios ácidos de Brønsted presentes no HPW, ao ácido de Lewis $\mathrm{Ti}^{4+}$ e à presença de grupo $-\mathrm{NH}_{2}$ na quitosana, atuando de forma sinergética. O material pode ser reutilizado pelo menos por seis vezes apresentando uma lixivição de 6,2 e 5,8\% de $\mathrm{Ti}^{4+}$ e HPW, respectivamente.

Chamidy [30] avaliaram a quitosana modificada com ácido sulfosalicílico e glutaraldeído na esterificação do ácido oleico com metanol usando $8 \%$ de catalisador em relação ao ácido oleico, durante 5 horas a $50^{\circ} \mathrm{C}$ e encontrou uma conversão do ácido óleico e $73,12 \%$, no entanto a estabilidade do catalisador frente a lixiviação e seu reuso não foram avaliados.

Diante do exposto, este trabalho teve como objetivo obter catalisadores à base de quitosana modificada pelo processo simples de acidificação com ácido clorídrico ou ácido sulfúrico, com o intuito de conferir propriedades ácidas à quitosana de forma a atuar como catalisador na reação de esterificação do ácido oleico com metanol.

\section{MATERIAIS E MÉTODOS}

Quitosana comercial com grau de desacetilação $\geq 75 \%$ (Sigma Aldrich - C3646 - Obtida da quitina proveniente da casca de camarão), ácido clorídrico (37\%, Vetec); ácido sulfúrico (PA, Vetec); álcool metílico 
(99,8\%, Vetec); álcool isopropílico (PA, Neon); hidróxido de sódio (Vetec); brometo de potássio (PA-ACS, Vetec); éter etílico (PA, Neon), ácido oleico (PA, Synth) foram utilizados como adquiridos.

\subsection{Síntese da quitosana acidificada}

A obtenção da quitosana acidificada foi realizada a partir da dissolução de $1,0 \mathrm{~g}$ de quitosana comercial em $50,00 \mathrm{~mL}$ de uma solução ácida (ácido clorídrico ou ácido sulfúrico) com concentração de $0,1 \mathrm{~mol} \mathrm{~L}^{-1}$, sob agitação magnética por um período de $10 \mathrm{~min}$. a $25^{\circ} \mathrm{C}$. Em seguida, a quitosana foi filtrada e seca em uma estufa a vácuo acoplada a uma bomba de duplo estágio a $135 \pm 1{ }^{\circ} \mathrm{C}$ por 2 horas [8]. Os catalisadores obtidos foramdenominados Q1 (quitosana acidificada com $\mathrm{HCl}$ ) e Q2 (quitosana acidificada com $\mathrm{H}_{2} \mathrm{SO}_{4}$ ). A quitosana comercial, usada como referência, foi denominada de QC.

\subsection{Caracterização físico-química dos catalisadores}

Para determinar o número de sítios ácidos de Brønsted disponíveis, $100 \mathrm{mg}$ do material foram postos em contato com NaOH $0,1 \mathrm{~mol} \mathrm{~L}^{-1}$ por 3 horas, sob agitação de aproximadamente $200 \mathrm{rpm}$. Após esse período, foram retiradas alíquotas da solução básica, adicionando 3 gotas de fenolftaleína, que em seguida, foram tituladas com $\mathrm{HCl} 0,1 \mathrm{~mol} \mathrm{~L}^{-1}$ para se verificar a quantidade de $\mathrm{NaOH}$ que reagiu com o material. A acidez foi determinada em mmol de $\mathrm{H}^{+}$por grama de material. Para determinação da basicidade, foram utilizadas as mesmas condições anteriormente citadas, no entanto, alíquotas foram agitadas em $\mathrm{HCl} 0,1 \mathrm{~mol} \mathrm{~L}^{-1}$ e tituladas com solução de $\mathrm{NaOH} 0,1 \mathrm{~mol} \mathrm{~L}^{-1}$. A basicidade foi determinada em mmol de $\mathrm{OH}^{-}$por grama do material.

Os espectros na região do infravermelho foram obtidos num espectrofotômetro da marca Smart Omnitransmission Nicolet iS10. As amostras foram preparadas na forma de pastilhas com a utilização de KBr. Estes espectros são resultado da média de varreduras numa resolução de $4 \mathrm{~cm}^{-1}$ e faixa de $400-4000 \mathrm{~cm}^{-1}$.

Os padrões de difração de raios X foram obtidos em um difratômetro Rigaku modelo mini - flex 600 , usando uma radiação $\mathrm{Cu} \mathrm{K} \alpha$ e $2 \theta=5-80^{\circ}$ com velocidade de varredura de $20^{\circ} \mathrm{min}^{-1}$ a $40 \mathrm{Kv}$ e $15 \mathrm{~mA}$.

As curvas termogravimétricas foram obtidas em uma termobalança SHIMADZU modelo TGA-50, taxa de aquecimento de $10^{\circ} \mathrm{C} \mathrm{min}^{-1} \mathrm{sob}$ atmosfera inerte com fluxo de nitrogênio, massa aproximadamente de $10 \mathrm{mg}$, com a temperatura variando de $20-800^{\circ} \mathrm{C}$.

A morfologia das partículas foi analisada através do microscópio eletrônico de varredura, marca Quanta 250, com uma tensão de $30 \mathrm{kV}$ a baixo vácuo.

\subsection{Avaliação Catalítica}

A reação de esterificação foi realizada em triplicata utilizando ácido oleico/metanol (razão molar 1:6), 5\% de catalisador em relação à massa de ácido pesada, durante 3 horas a uma temperatura de $120^{\circ} \mathrm{C}$. Posteriormente, o catalisador foi separado por filtração. Em seguida, fez-se a lavagem da reação utilizando água/éter etílico (v/v\% 1:1). Nessa etapa, ocorre a separação de fases, em que na fase orgânica se encontram o éter, os ésteres formados e o ácido remanescente, e, na fase aquosa, água e metanol, que foi descartada. Em seguida, o éter foi evaporado por aquecimento a $60^{\circ} \mathrm{C}$. Após evaporação do éter, foram retiradas alíquotas, as quais foram devidamente pesadas e solubilizadas numa mistura de álcool etílico e éter numa proporção 2:1 e, em seguida, tituladas com uma solução padronizada de $\mathrm{NaOH} 0,1 \mathrm{~mol} \mathrm{~L}^{-1}$. A conversão da reação foi calculada a partir da seguinte equação:

$$
\text { Conversão }(\%)=\mathrm{C}_{\mathrm{NaOH}} \times \mathrm{V}_{\mathrm{NaOH}} \times \mathrm{MM}_{\text {Ácido }} \times 100 / 10^{3} \text { x m } \mathrm{m}_{\text {alíquota }}
$$

Para a realização do teste de lixiviação, os catalisadores sintetizados foram testados na reação padrão de esterificação utilizando as mesmas condições já citadas. Após 30 minutos, o catalisador foi filtrado à quente e, em seguida, o filtrado foi posto novamente no sistema por mais 2 horas e 30 minutos. Alíquotas foram retiradas durante a filtração, e em intervalos de 30 minutos até o término da reação, e tratadas como já descrito para a avaliação catalítica.

Para avaliação da capacidade de reutilização, o catalisador foi empregado na reação de esterificação em condições descritas, sendo posteriormente filtrado, lavado com metanol, seco à $60^{\circ} \mathrm{C}$ em estufa por 2 horas, e por fim, utilizado em uma nova reação. O procedimento descrito foi realizado sucessivamente, até que houvesse perda significativa de atividade catalítica. 
Todos os experimentos foram realizados em triplicata, utilizando média e desvio padrão. Aplicaram-se os testes Q, para rejeição de valor anômalo, utilizando intervalo de 95\% de confiança em todos dados obtidos a partir das análises de conversão da reação. Os resultados foram expressos em: Resultado obtido na análise \pm $2 \mathrm{~s}$.

\section{RESULTADOS E DISCUSSÃO}

O número de sítios ácidos e,ou básicos de Brønsted presentes nos materiais é mostrado na Figura 1. A quitosana comercial apresenta acidez, porém o número de sítios ácidos não é suficiente para promover a reação de esterificação. Observa-se que o número de sítios ácidos de Brønsted dos materiais Q1 e Q2 aumentou de forma significativa em relação à quitosana comercial. A quitosana possui três grupos reativos funcionais, um grupo amino na posição C-2, e duas hidroxilas, uma primária e outra secundária, nas posições C-3 e C-6, portanto, um dos fatores responsáveis pela acidez do material é a protonação do grupo amino. Outro fator é a interação dos grupos reativos com os ácidos por meio de ligação hidrogênio promovendo a estabilização destes na estrutura. Os materiais Q1 e Q2 não apresentaram basicidade dentro dos limites de detecção do método utilizado.

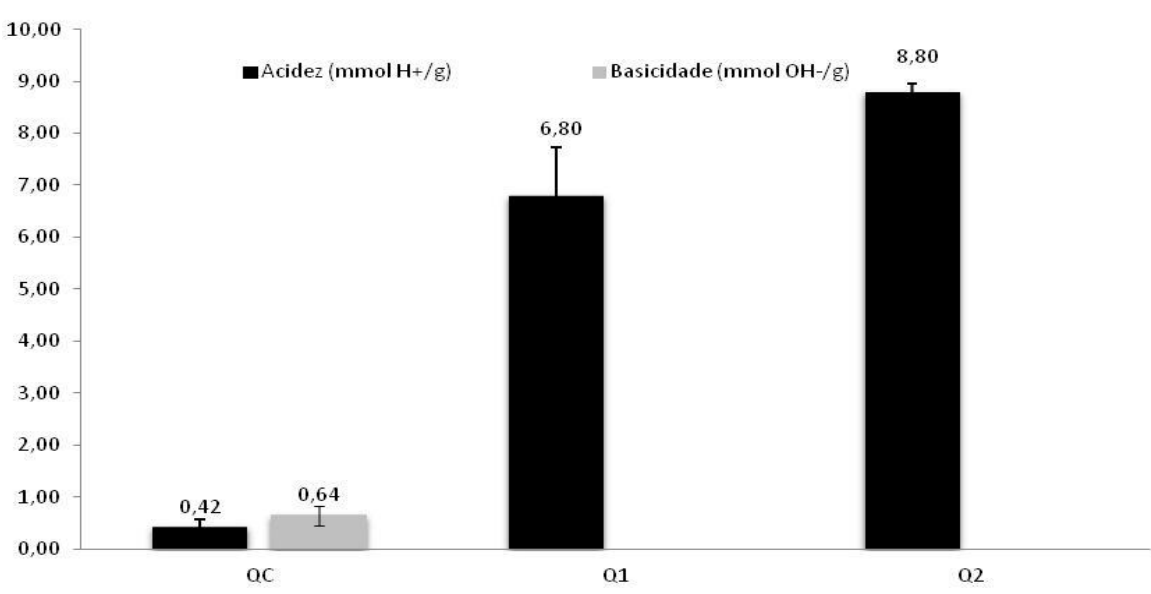

Figura 1: Concentração de $\mathrm{H}^{+}$para os materiais QC, Q1 e Q2 e de $\mathrm{OH}^{-}$para o material QC, em mmol g ${ }^{-1}$. Condições utilizadas: Tempo: $3 \mathrm{~h}$, temperatura: $25^{\circ} \mathrm{C}$.

A região do espectro eletromagnético correspondente à região do infravermelho onde ocorre a maior parte das energias de vibrações moleculares para a quitosana está entre 2000 e $700 \mathrm{~cm}^{-1}$ (Figura 2). Observase ainda mudanças estruturais da quitosana após acidificação com ácido clorídrico ou ácido sulfúrico [25]. O espectro de infravermelho da quitosana comercial (QC) apresentou as bandas correspondentes: ao estiramento axial de $\mathrm{OH}$ em $3425 \mathrm{~cm}^{-1}$ (não mostrado), havendo possivelmente sobreposição da banda de estiramento $\mathrm{N}-\mathrm{H}$; deformação axial da carbonila do grupo amida em $1650 \mathrm{~cm}^{-1}$; deformação angular (fora do plano) de $\mathrm{NH}_{2}$ em $1558 \mathrm{~cm}^{-1}$; deformação axial de $-\mathrm{CN}$ de amida em $1420 \mathrm{~cm}^{-1}$ e deformação axial de $-\mathrm{CN}$ de grupamentos amino em $1378 \mathrm{~cm}^{-1}$, além de bandas de estruturas polissacarídicas na região de $890-1150$ $\mathrm{cm}^{-1}[26,31]$. 


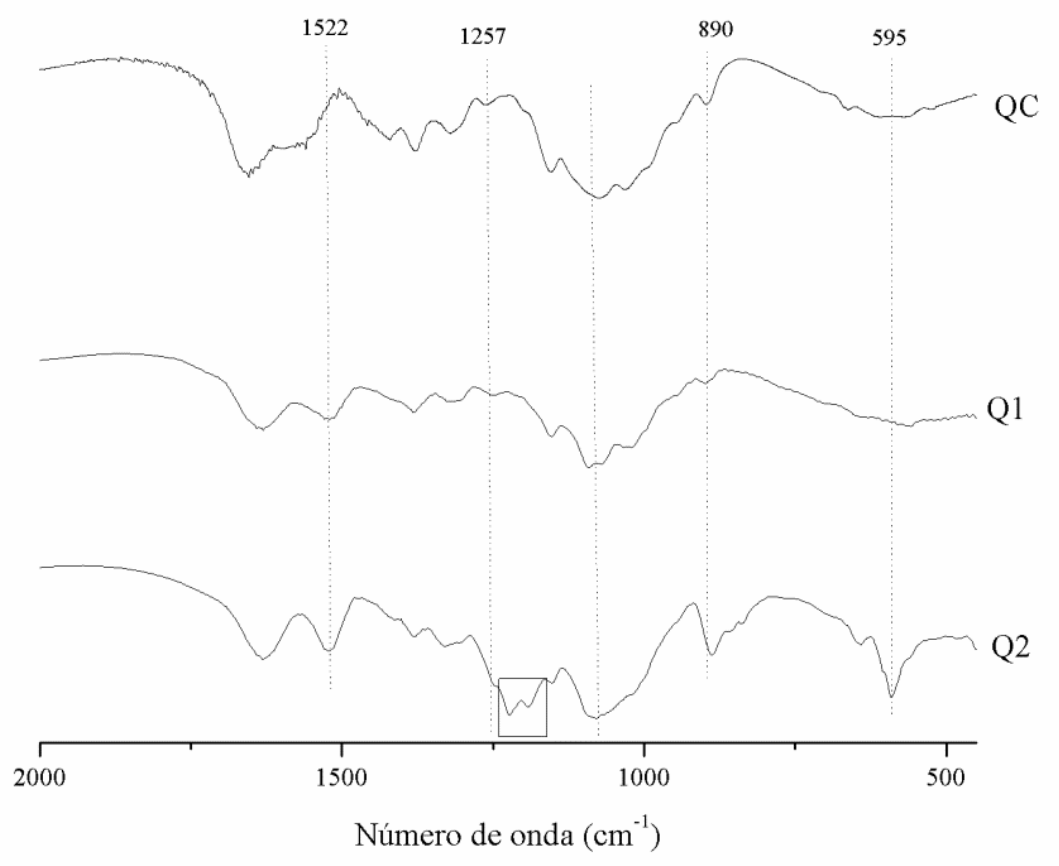

Figura 2: Espectros na região do infravermelho para as amostras QC, Q1 e Q2.

As modificações no momento dipolar do material QC após acidificação são decorrentes da interação do próton do ácido com os grupos terminais do biopolímero bem como da sulfatação no caso específico do material Q2. Observa-se que as bandas correspondentes ao estiramento e,ou deformação do grupo amino nas regiões 1565 e $1380 \mathrm{~cm}^{-1}$ sofreram deslocamento para menores números de onda.

Além disso, foi confirmado que tanto o ácido clorídrico quanto o ácido sulfúrico não afetaram de forma significativa as ligações glicosídicas da quitosana, que apresentam bandas nas regiões entre 897 e 1153 $\mathrm{cm}^{-1}$.

Para o material Q2 foi possível observar bandas de absorção referentes ao estiramento simétrico e assimétrico relativas à presença do grupo sulfato em 590 e $1222 \mathrm{~cm}^{-1}$, respectivamente [32]. O deslocamento e aumento de intensidade da banda a $890 \mathrm{~cm}^{-1}$ pode ser atribuído à contribuição do grupo C-O-S confirmando a sulfatação da quitosana [33].

A Figura 3 mostra que o padrão de difração de raios $X$ para a quitosana comercial apresenta picos em torno de $2 \theta=10^{\circ}$ e $2 \theta=20^{\circ}$, sendo o pico $2 \theta=20^{\circ}$ o mais intenso. A estrutura da quitosana é conhecida como um polímero linear e extenso, tendo em sua estrutura vários grupos amino, hidroxila e amida que interagem através das ligações de hidrogênio inter- e intramoleculares, dando ao material, características organizacionais semicristalinas [34,35]. Quando comparado ao padrão JCPDS (039-1894) da quitosana que apresenta picos bem definidos em 28 e $34^{\circ}$, observa-se a baixa cristalinidade da quitosana comercial utilizada neste trabalho, provavelmente devido aos tratamentos químicos durante o processo de extração da quitina da casca do camarão. 

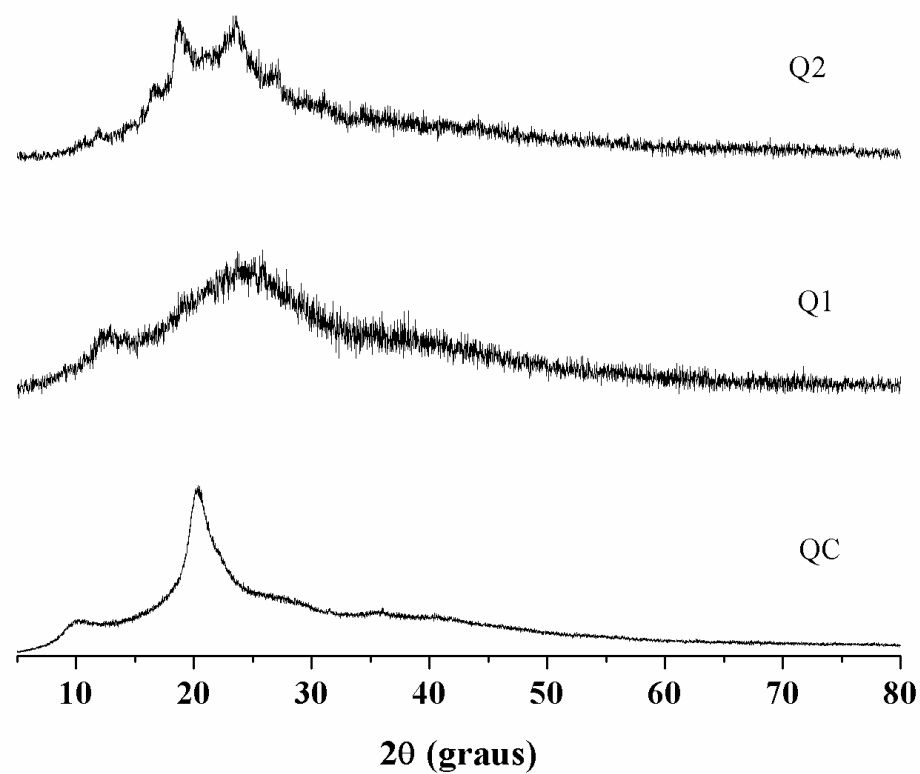

Figura 3: Padrões de difração de raios $X$ das amostras de quitosana comercial (QC) e os materiais acidificados com ácido clorídrico Q1 e ácido sulfúrico Q2.

Nos padrões de difração de raios $\mathrm{X}$ referentes aos materiais acidificados, observa-se que para o material acidificado com $\mathrm{HCl}$, houve um alargamento e deslocamento do pico em torno de $2 \theta=20^{\circ}$, evidenciando uma maior desestruturação da quitosana. Este fato pode ser atribuído ao fato do ácido clorídrico favorecer as interações eletrostáticas entre as cadeias poliméricas, resultando em uma instabilidade estrutural e consequente desorientação dos planos cristalinos, no momento da acidificação [34,36]

Já para o material Q2 observam-se picos que indicam uma maior organização estrutural, no entanto com valores de $2 \Theta$ deslocados em relação à quitosana comercial. Estes deslocamentos podem ser resultantes das interações entre o grupo amino protonados da quitosana e os íons sulfato, resultando em uma maior organização dos planos da quitosana após o processo de acidificação, quando comparado com a amostra acidificada com $\mathrm{HCl}[33,36,37]$.

A curva termogravimétrica do material QC (Figura 4) indicou a presença de dois eventos térmicos. O primeiro com perda de massa em torno de $7,74 \%$ numa faixa de temperatura de aproximadamente 54 a $110^{\circ}$ $\mathrm{C}$, referente à perda de água. O segundo evento corresponde a uma perda de massa de $35,41 \%$ entre $100 \mathrm{a}$ $350^{\circ} \mathrm{C}$, referente à decomposição térmica e oxidativa da quitosana com eliminação de compostos orgânicos voláteis, sendo esta a mais significativa, tendo em vista que a quitosana é composta de grupos amino ligados por toda sua extensão polimérica [38]. 


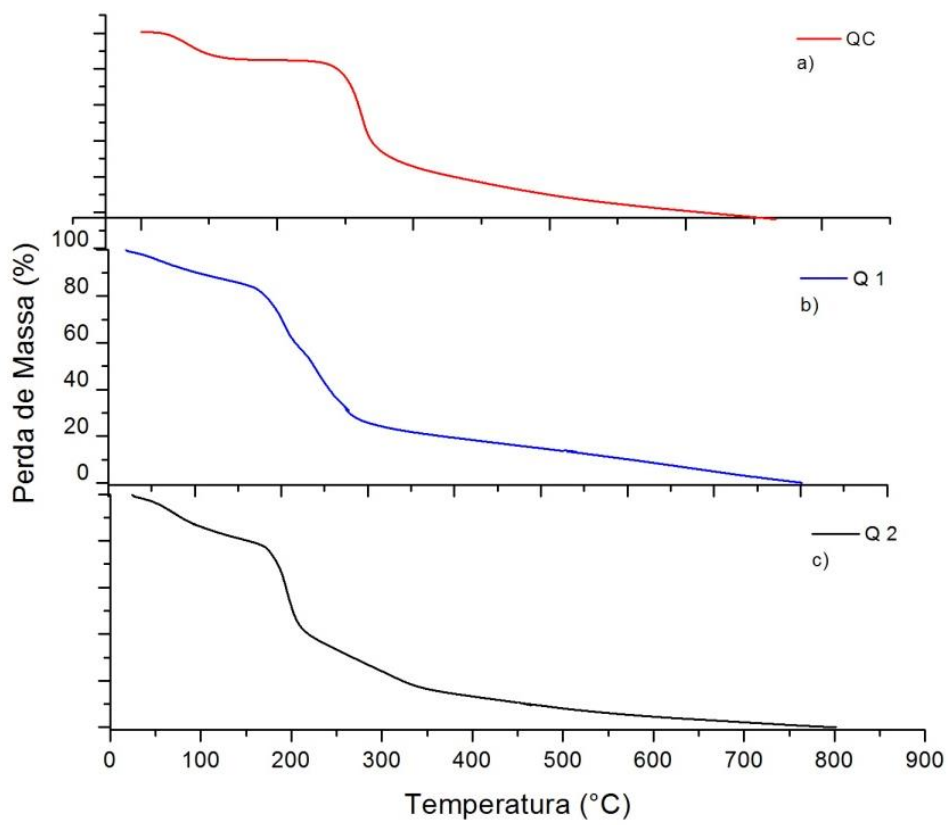

Figura 4: Curvas termogravimétricas das amostras quitosana comercial (a) e os materiais acidificados com ácido clorídrico (b) e ácido sulfúrico (c).

O material Q1 (Figura 4a) apresenta três eventos térmicos: o primeiro relacionado à perda de água, que corresponde a aproximadamente $15,5 \%$, na faixa de temperaturas entre $20-170^{\circ} \mathrm{C}$; o segundo evento, que foi o mais expressivo entre os três, refere-se à perda de grupos do material orgânico, que corresponde a $56,6 \%$, na faixa de temperatura entre $170-295^{\circ} \mathrm{C}$, já o terceiro evento está relacionado à decomposição e carbonização do material, em aproximadamente $27,9 \%$ até $800^{\circ} \mathrm{C}$ [38-41].

Já para o material Q2, foi observada a presença de quatro eventos térmicos: o primeiro evento que ocorre na faixa de temperatura de $26-165^{\circ} \mathrm{C}$ correspondendo a uma perda de massa de $19,5 \%$ está relacionada,principalmente, à perda de água adsorvida na superfície do material; o segundo evento (perda de massa de $39,5 \%$ entre $165-211^{\circ} \mathrm{C}$ ) e o terceiro evento ( perda de massa de $24,3 \%$ e faixa de temperatura de 211-337 ${ }^{\circ} \mathrm{C}$ ), estão associados à liberação de compostos orgânicos, e o quarto evento de perda de massa foi de aproximadamente $16,7 \%$ entre as temperaturas de $337-800^{\circ} \mathrm{C}$, correspondendo à perda dos grupos sulfatos e carbonização do material[41,42].

A análise do material Q2 evidenciou uma maior estabilidade térmica na mesma faixa de temperatura que o material Q1 (entre $160-300^{\circ} \mathrm{C}$ ). Isso pode ser explicado pelas fortes interações covalentes existentes resultantes do processo de reticulação promovida pelos grupos sulfato [32,42-44].

Com a análise das curvas termogravimétricas foi possível perceber que após a acidificação o material Q2 apresentou características mais hidrofílicas por conta do aumento de perda de água $(\mathrm{QC}=7,74 ; \mathrm{Q} 1=15,5$; $\mathrm{Q} 2=19,5 \%$ ) em cada material. Este fato tem influência direta do comportamento dos materiais durante a reação de esterificação uma vez que reagentes e produtos hidrofílicos [25].

A Figura 5 mostra as micrografias obtidas por microscopia eletrônica de varredura para os três materiais.

A quitosana comercial, QC, apresenta uma estrutura fibrosa, textura rugosa com ranhuras irregulares e com partículas superficiais instáveis. O material acidificado com ácido clorídrico, Q1, apresenta excesso de ranhuras e ressecamento, sugerindo facilidade de escamação e desprendimento. Isso, provavelmente, facilita o processo de degradação e posterior lixiviação quando em contato com meio reacional.

Já para o material Q2 é possível que o material Q2 apresenta uma superfície mais compacta e lisa, quando comparada às amostras QC e Q1. Apresenta ainda partículas superficiais visivelmente agregadas sem indícios de desprendimento, com arestas livres que podem facilitar uma maior proximidade com sítios ativos no momento da reação, no entanto podem também ser susceptíveis ao desprendimento. [4,8,42]. 

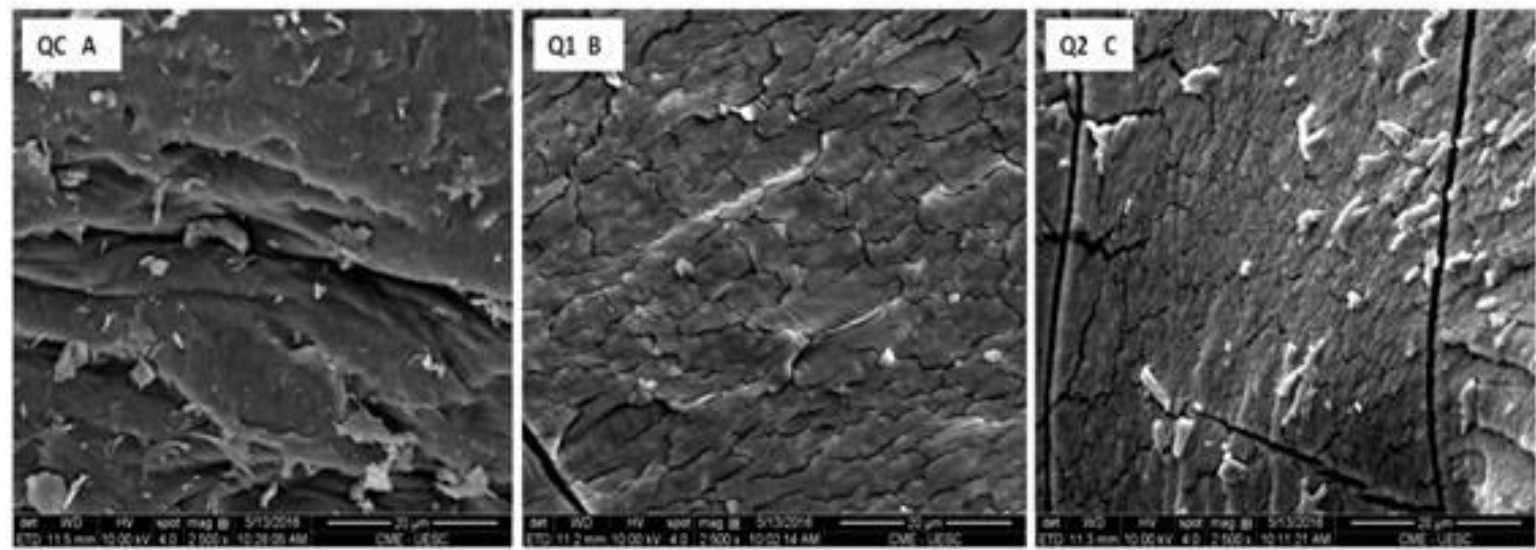

Figura 5: Micrografias das três amostras de quitosana com aumento de 400 X. QC, Q1 e Q2.

A Figura 6 mostra os resultados da conversão do ácido oleico na esterificação com metanol.

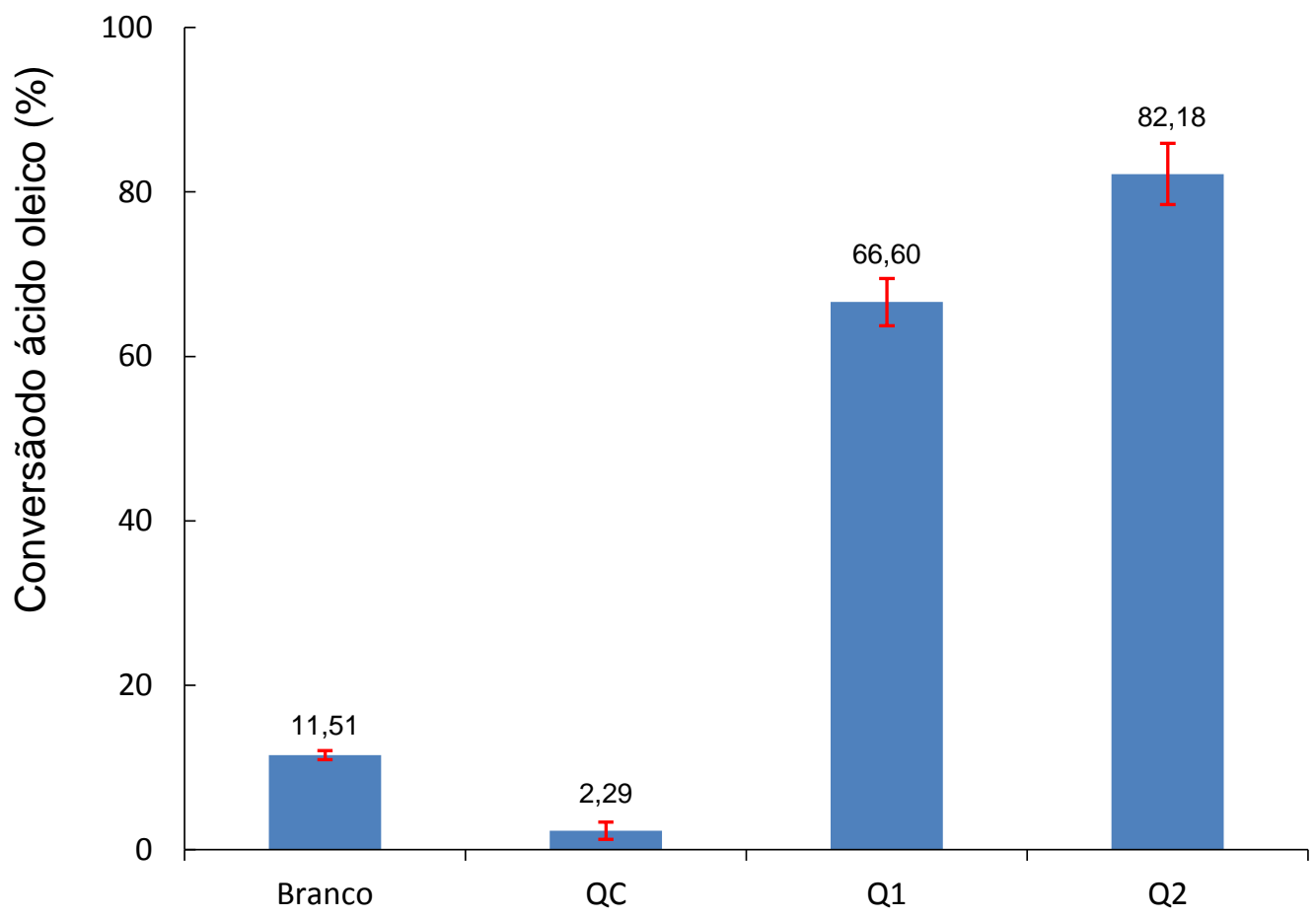

Figura 6: Conversão do ácido oleico utilizando materiais QC, Q1 e Q2 como catalisador. (Condições reacionais - Razão molar ácido oleico/metanol (1:6), 5\% de catalisador, $3 \mathrm{~h}, 120^{\circ} \mathrm{C}$ ). Os valores da conversão para os materiis QC, Q1 e Q2 foram descontados do valor do branco.

É importante ressaltar que todos os valores de conversão apresentados para os materiais QC, Q1 e Q2 foram descontados do valor da conversão autocatalítica (Branco). Como já dito, apesar da quitosana possuir sítios ácidos em sua estrutura, a quantidade não foi suficiente para catalisar a reação. Já os materiais acidificados Q1 e Q2 apresentaram altas taxas de conversão, como esperado, devido ao fato de apresentarem maior quantidade de sítios ácidos. A maior atividade do material Q2 pode ser atribuída à presença do grupo sulfato. No entanto, há a necessidade de verificação da estabilidade destes materiais nas condições da reação [45].

Com a realização do teste de lixiviação é possível avaliar se houve ou não perda de grupos funcionais responsáveis pela atividade, que migraram para o meio reacional, favorecendo a continuidade da reação com 
a contribuição da catálise homogênea. Os resultados dos testes de lixiviação, para os materiais Q1 e Q2, são mostrados nas Figuras 7 e 8, respectivamente.

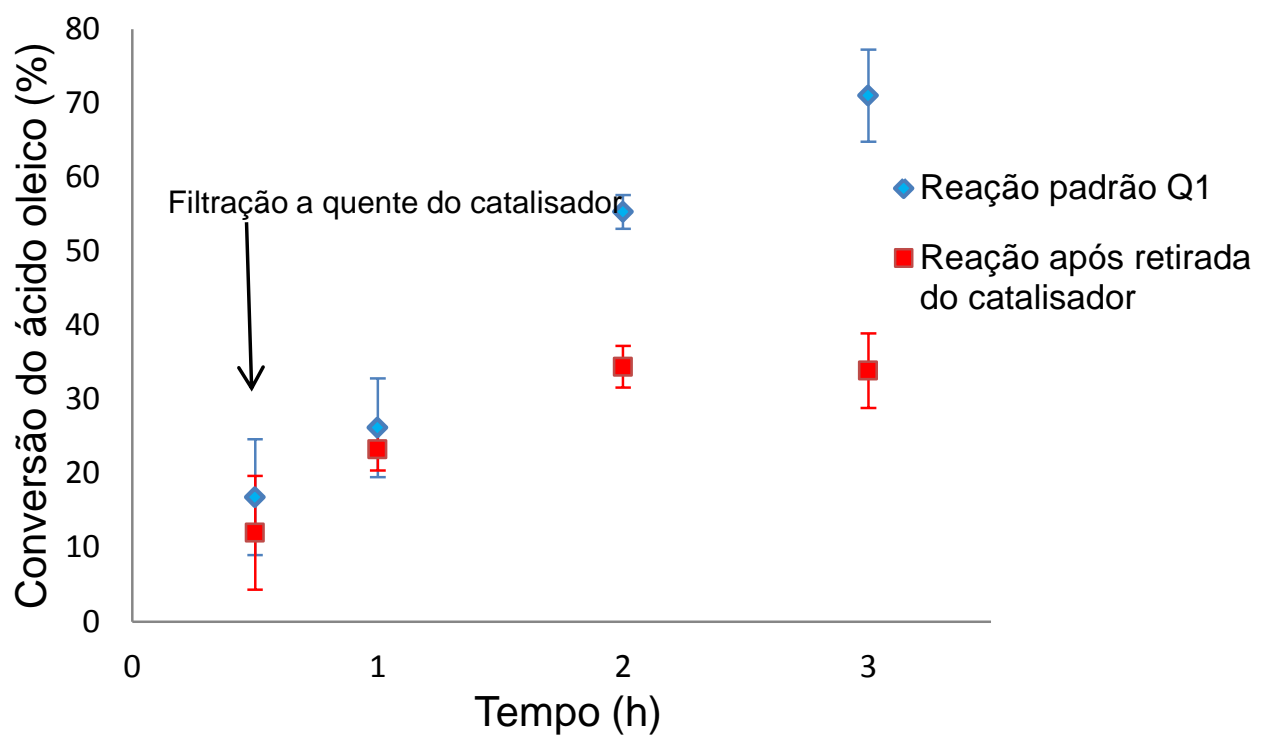

Figura 7: Teste de lixiviação utilizando catalisador Q1 (Condições reacionais - razão molar ácidooleico/metanol (1:6); $5 \%$ de catalisador; $3 \mathrm{~h}$ com retirada de catalisador com $30 \mathrm{~min} ., 120^{\circ} \mathrm{C}$ )

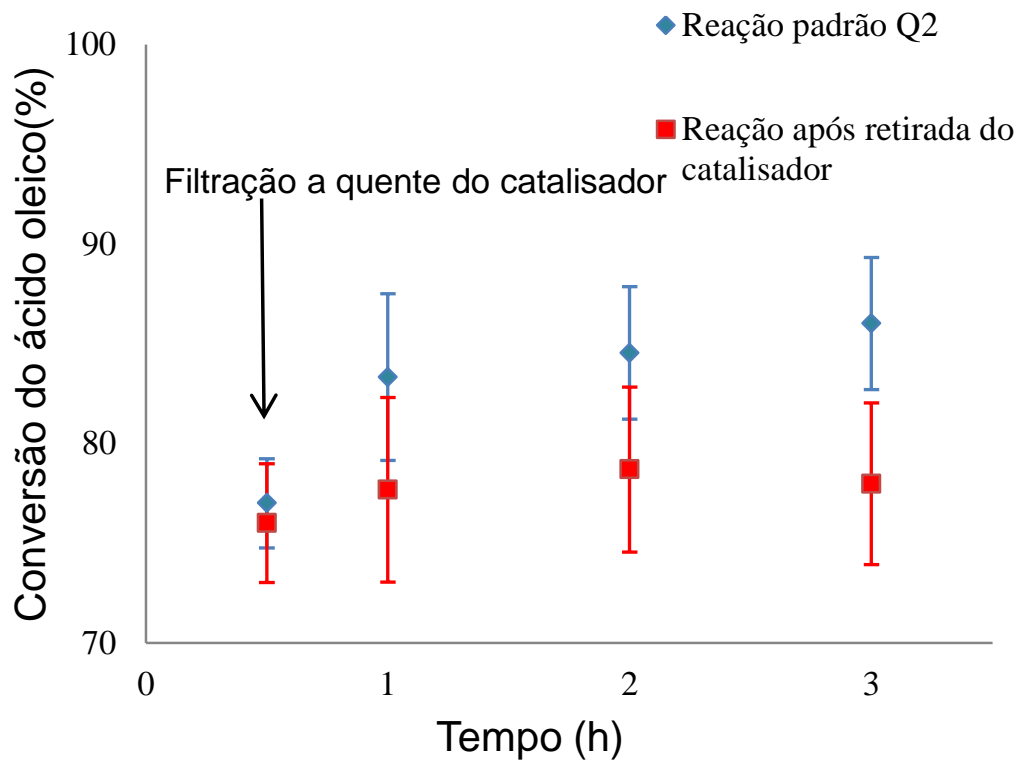

Figura 8: Teste de lixiviação utilizando catalisador Q2 (Condições reacionais - razão molar ácido oleico/metanol (1:6); 5 $\%$ de catalisador; $3 \mathrm{~h}$ com retirada de catalisador com $30 \mathrm{~min} ., 120^{\circ} \mathrm{C}$ ). 
Observa-se que, quando comparado ao material Q2, a atividade catalítica apresentada pelo material Q1 pode ser seguramente atribuída à lixiviação parcial de espécies ativas para o meio reacional. Este fato pode ser devido à interação existente entre o suporte e o sítio ácido (próton). Como há a formação de íons amônio, o próton do ácido interage eletrostaticamente com o grupo funcional amina da quitosana, podendo facilmente migrar para o meio reacional, e dessa forma influenciando diretamente na conversão da reação [45].

Com relação ao material Q2 pode-se inferir que o material apresentou estabilidade frente à reação de esterificação nas condições analisadas, uma vez que, após a retirada do catalisador com 30 min., a conversão permaneceu constante dentro do erro experimental. Essa maior estabilidade quando comparada ao material Q1 pode estar relacionada à capacidade reticulante do íon sulfato, o que promove resistência mecânica e estabilidade na cadeia polimérica da quitosana, como foi comprovado pela caracterização do material. Esta estrutura mais organizada pode ter favorecido interações entre os grupos sulfato e os prótons reduzindo assim a migração para o meio reacional.

Diante do comportamento do material Q2 frente à lixiviação nas condições avaliadas, este foi então, reutilizado em sucessivas reações de forma a verificar a estabilidade da estrutura sulfatada. A partir da Figura 9 é possível observar que o material Q2 apresentou atividade catalítica apenas até o segundo ciclo reacional.

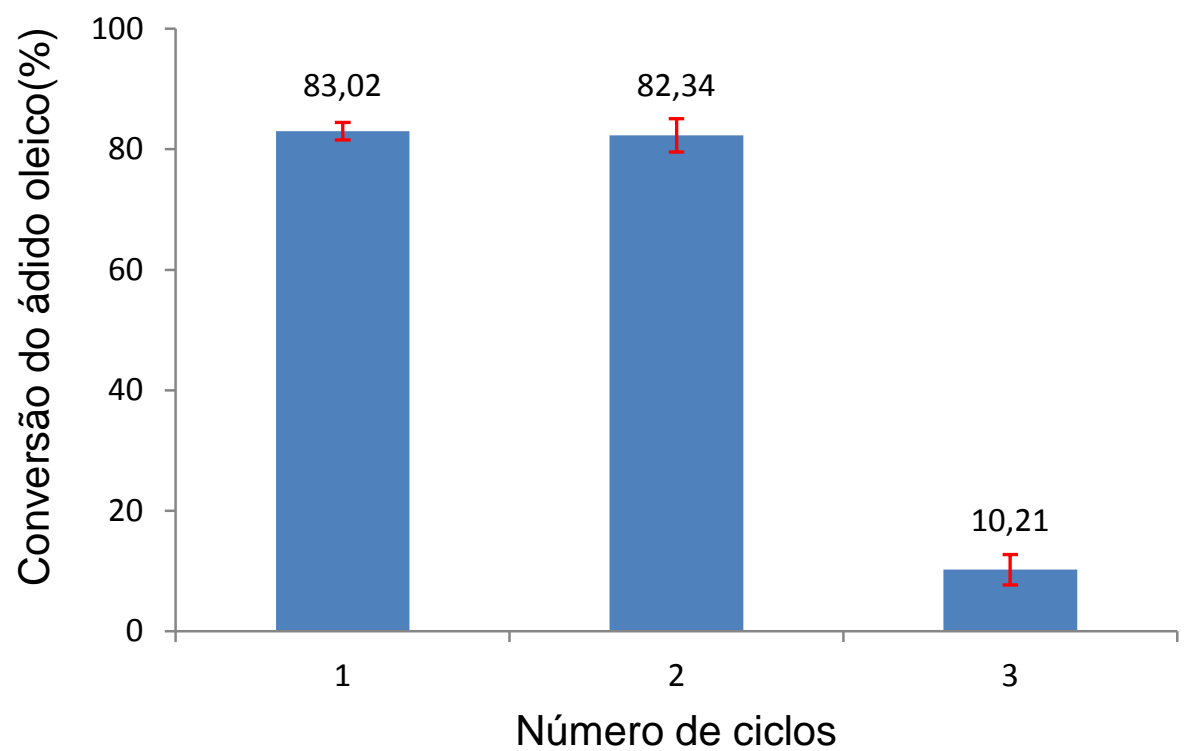

Figura 9: Teste de reutilização do catalisador acidificado com $\mathrm{H}_{2} \mathrm{SO}_{4}$ ( Condições reacionais - razão molar ácido oleico/metanol (1:6); $5 \%$ de catalisador;3 $\mathrm{h} ; 120^{\circ} \mathrm{C}$ ). Após cada ciclo o catalisador foi filtrado, lavado com metanol e seco à $60^{\circ} \mathrm{C}$ em estufa por 2 horas.

Este resultado a princípio parece discordante com o teste de lixiviação mostrado na Figura 8, o qual sugere uma estabilidade do material nas condições reacionais. Para um maior entendimento sobre o comportamento do material após os ciclos reacionais e, consequentes processos de lavagem com metanol, foram realizadas as análises por espectrometria na região do infravermelho após cada ciclo (Figura 10). Para efeito comparativo, os espectros da quitosana comercial e o catalisador antes da reação também são mostrados.

Observa-se uma redução significativa das bandas relacionadas à presença do grupo sulfato na estrutura da quitosana $\left(1220,890\right.$ e $\left.590 \mathrm{~cm}^{-1}\right)$ após cada ciclo. Sendo mais pronunciado entre os ciclos 1 e 2 , onde provavelmente ocorreu o desprendimento parcial dos grupos sulfato. Diante dessas evidências conclui-se que a conversão catalítica apresentada para o segundo ciclo pode ser atribuída à catalise homogênea e que após o terceiro e quarto ciclos o material Q2 não apresenta sítios ácidos suficientes para catalisar a reação, apresentando conversão da mesma ordem de magnitude da quitosana comercial.

No entanto vale ressaltar que as análises qualitativas de EDX do material Q2 após o quarto ciclo ainda 
mostra a presença de enxofre mesmo após a completa desativação do material. A presença da banda a 590 $\mathrm{cm}^{-1}$ no espectro das amostras reutilizadas também evidencia a presença do enxofre nas amostras. Provavelmente, estes grupos sulfatos, apesar de presentes, não estão mais acessíveis para atuar como sítio ativo.

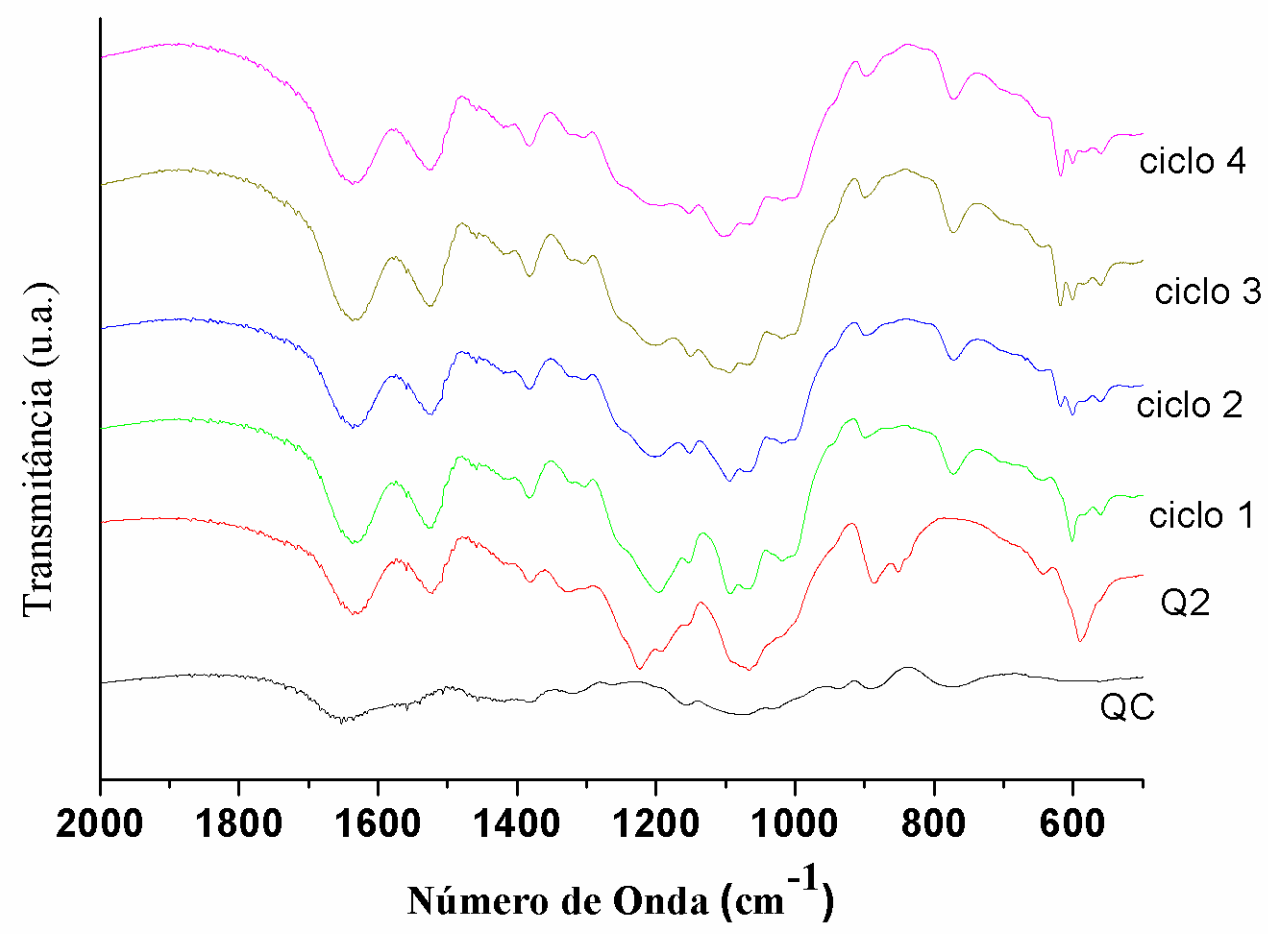

Figura 10: Espectros na região do infravermelho do material Q2 após cada ciclo de reutilização.

Para confirmar esta hipótese, foi realizado um experimento simultâneo de lixiviação e reutilização cujo resultado é mostrado na Figura 11. Observa-se que este experimento confirma os resultados apresentados nas Figuras 8, 9 e 10 mostrando que quando usado apenas uma vez o material Q2 apresenta estabilidade frente à lixiviação, no entanto após o processo de lavagem com metanol, secagem e reutilização o material já apresenta uma queda significativa na atividade catalítica devido ao desprendimento dos grupos sulfato e consequentemente dos prótons que estão em interação com estes. $\mathrm{O}$ segundo teste de lixiviação mostrou que houve a migração das espécies ativas para o meio reacional, resultando em uma conversão de $62 \%$ mesmo após a retirada do catalisador a quente. No terceiro e quarto ciclos já não apresenta atividade significativa com 30 min. de reação. 


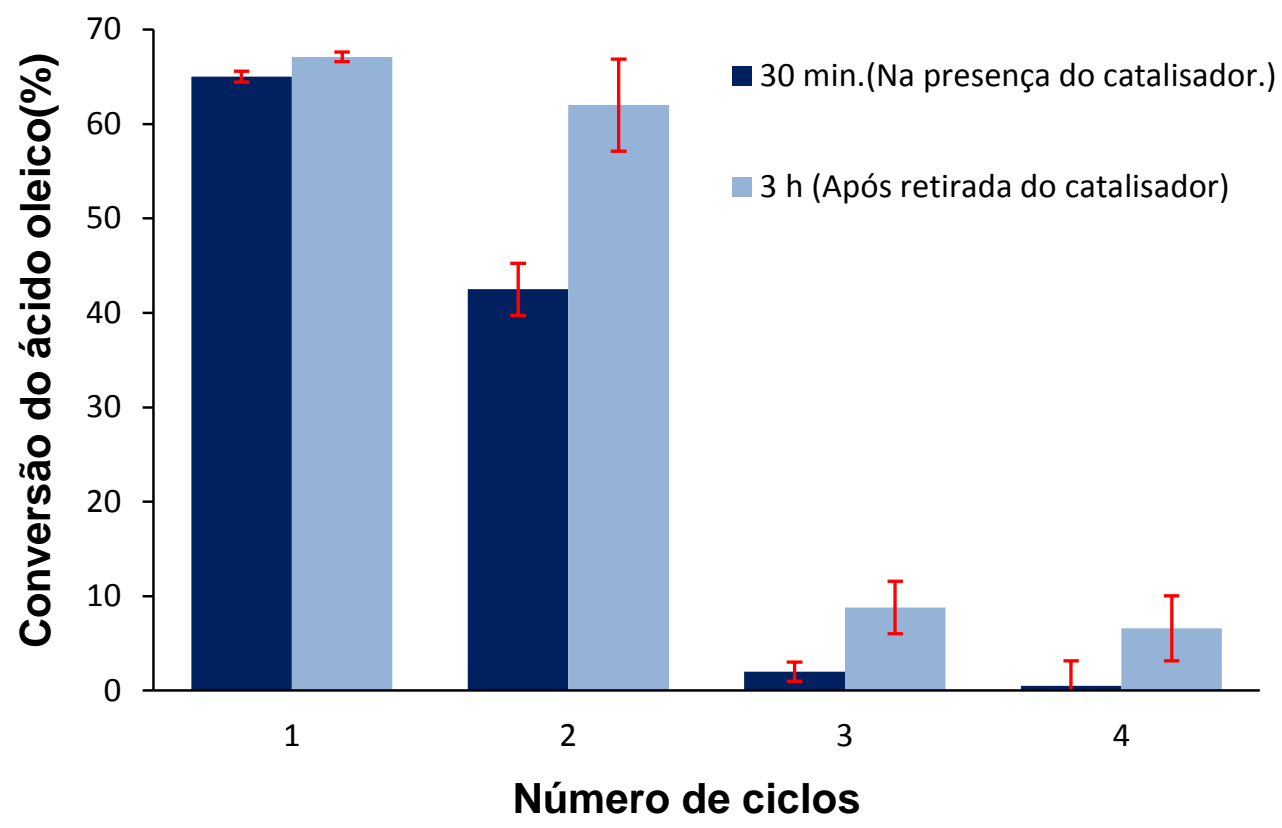

Figura 11: Testes de lixiviação e reutilização simultâneos. (O catalisador é filtrado à quente com 30 min de reação, lavado e seco e posto em um novo ciclo de 30min. O filtrado é posto nas condições de reação por mais $2,5 \mathrm{~h}$ )

Enfim, o material Q2 apesar de apresentar boa atividade catalítica e estabilidade no primeiro ciclo de reação, o mesmo é desativado em decorrência da perda dos grupos ativos. Vale ressaltar que o material foi facilmente separado e filtrado com perda mínima de massa, o que indica que não houve solubilização significativa do sólido no meio reacional. Isto mostra que o método de síntese utilizado apesar de ter possibilitado um aumento significativo na atividade catalítica quando comparado com a quitosana comercial, o material resultante não apresenta estabilidade suficiente para atuar como catalisador heterogêneo nas condições aqui avaliadas. Estes resultados mostram a importância do estudo detalhado dos processos de lixiviação e reutilização dos catalisadores heterogêneos [45].

\section{CONCLUSÕES}

A modificação da quitosana com soluções diluídas de ácidos inorgânicos é um método simples e eficaz para a preparação de catalisador heterogêneo ácido. No entanto, apesar da modificação com o ácido sulfúrico resultar em um catalisador heterogêneo ativo na esterificação do ácido oleico, há evidência que o material desativa após dois ciclos de reação por lixiviação das espécies responsáveis pela atividade catalítica.

\section{AGRADECIMENTOS}

JOC agradece a CAPES pela bolsa de mestrado. RRM agradece à FAPESB pela bolsa de iniciação científica. RSC agradece a FAPESB e a CAPES pelo apoio financeiro à pesquisa. Os autores agradecem ao Centro de Microscopia da UESC pelas análises de MEV-EDX. 


\section{BIBLIOGRAFIA}

[1] SHELDON, R.A., ARENDS, I., HANEFELD, U., Green Chemistry and Catalysis, 2 ed.,Weinheim, John Wiley \& Sons, 2015.

[2] VAIDYA, A.A., GAUGLER, M., SMITH, D. A., "Green route to modification of wood waste, cellulose and hemicellulose using reactive extrusion", Carbohydrate Polymers, v.136, pp.1238-1250, 2016.

[3] HAMED, I., ÖZOGUL, F., REGENSTEIN, J.M., "Industrial applications of crustacean by-products (chitin, chitosan, and chitooligosaccharides): A review", Trends in Food Science \& Technology, v. 48, pp.:40-50, 2016.

[4] CAMPANA-FILHO, S.P., BRITTO, D., CURTI, C., et al., "Extração, estrutura e propriedades de $\alpha$ e $\beta$ quitina", Química Nova, v. 30, pp. 644-650, 2007.

[5] QAVAMI, N., NAGHDI, B. H., MEHREGAN, M., et al., "Overview on Chitosan as a valuable ingredient and biostimulant in pharmaceutical industries and agricultural products", Trakia Journal of Sciences, v. 15, pp.83-91, 2017.

[6] KADOUCHE, S., FARHAT, M. , LOUNICI, H., et al., "Low Cost Chitosan Biopolymer for Environmental Use Made from Abundant Shrimp Wastes", Waste and Biomass Valorization, v. 8, pp.401406, 2017.

[7] SINGH, R., SHITIZ, K., SINGH, A., "Chitin and chitosan: biopolymers for wound management", International Wound Journal, v.14, pp. 1276-1289, 2017.

[8] MARTINS C P. Quitosana como catalisador na transesterificação do óleo de soja para produção de biodiesel, Dissertação de Mestrado, Universidade de Brasília, Brasília, DF, Brasil, 2008.

[9] MACKAY, R.G, TAIT, J.M., eds. Handbook of chitosan research and applications., New York, Nova Science Publishers, Inc., 2012.

[10] WANG, M., MA, Y., SUN, Y., et al., "Hierarchical porous chitosan sponges as robust and recyclable adsorbents for anionic dye adsorption”, Scientific reports, v.7, pp.18054, 2017

[11] KHAN, S.A., KHAN, S.B., KAMAL, T., et al., "Recent Development of Chitosan Nanocomposites for Environmental Applications", Recent Patents on Nanotechnology, v. 10, pp.181-188, 2016

[12] LUCENA, G.L., SILVA, A.G., HONÓRIO, L.M.C., et al., "Avaliação da capacidade de adsorção da quitosana quartenizada na remoção de íons $\mathrm{Cu}^{2+}$ e $\mathrm{Cr}^{3+»}$, Revista Virtual de Química, v.7, pp. 2166-2179, 2015.

[13] BAYRAMOĞLU, G.,"Methacrylated Chitosan Based UV Curable Support for Enzyme Immobilization", Materials Research, v.20, pp. 452-459, 2017.

[14] REZGUI, S., AMRANE, A., FOURCADE, F., et al., "Electro-Fenton catalyzed with magnetic chitosan beads for the removal of Chlordimeform insecticide", Applied Catalysis. B, Environmental, v. 226, pp.346 $359,2018$.

[15] KAYSER, H., PIENKOß, F., MARÍA, P.D., "Chitosan-catalyzed biodiesel synthesis: Proof-of-concept and limitations", Fuel, v.116, pp. 267-272, 2014.

[16] CHEN, G., LIU, J., QI, Y., et al., "Biodiesel production using magnetic whole-cell biocatalysts by immobilization of Pseudomonas mendocina on $\mathrm{Fe}_{3} \mathrm{O}_{4}$-chitosan microspheres", Biochemical Engineering Journal, v.113, pp.86-92, 2016.

[17] RAMOS, L.P., KNOTHE, G., GERPEN, J.V., et al., eds. Manual de Biodiesel, São Paulo, Edgard Blucher, 2006.

[18] AVHAD, M.R., MARCHETTI, J.M., "A review on recent advancement in catalytic materials for biodiesel production", Renewable and Sustainable Energy Reviews, v.50, pp.696-718, 2015.

[19] ARANSIOLA, E.F., OJUMU, T.V., OYEKOLA,O.O., et al., "A review of current technology for biodiesel production: State of the art", Biomass and Bioenergy, v. 61, pp. 276-297, 2014.

[20] BASKAR, G., AISWARYA, R., "Trends in catalytic production of biodiesel from various feedstocks", Renewable and Sustainable Energy Reviews, v.57, pp. 496-504, 2016.

[21] LEE, A.F., BENNETT, J.A., MANAYIL, J.C, et al., "Heterogeneous catalysis for sustainable biodiesel production via esterification and transesterification",Chemistry Society Review, v. 4, pp.7887-7916, 2014.

[22] HE, B., SHAO, Y., LIANG, M., et al., "Biodiesel production from soybean oil by guanidinylated chitosan", Fuel, v. 159, pp. 33-39, 2015. 
[23] LIANG, M., HE, B., SHAO, Y., et al., "Preparation and catalytic performance of N-[(2-Hydroxy-3trimethylammonium) propyl] chitosan chloride $/ \mathrm{Na}_{2} \mathrm{SiO}_{3}$ polymerbasedcatalyst for biodiesel production", Renewable Energy, v. 88, pp. 51-57, 2016.

[24] FEREIDOONI, L., MEHRPOOYA, M., "Experimental assessment of electrolysis method in production of biodiesel from waste cooking oil using zeolite/chitosan catalyst with a focus on waste biorefinery", Energy Conversion and Management, v. 147, pp. 145-154, 2017.

[25] LIN, Y.K., NGUYEN, V,H., YU, J.C.C., et al., "Biodiesel production by pervaporation-assisted esterification and pre-esterification using graphene oxide/chitosan composite membranes", Journal of the Taiwan Institute of Chemical Engineers, v. 79, pp. 23-30, 2017.

[26] CAETANO, C.S., CAIADO, M., FARINHA, J., et al., "Esterification of free fatty acids over chitosan with sulfonic acid groups”, Chemical Engineering Journal, v. 230, pp. 567-572, 2013.

[27] BONAZZA, H.L, MANZO, R.M., DOS SANTOS, J.C.S., et al., "Operational and Thermal Stability Analysis of Thermomyces lanuginosus Lipase Covalently Immobilized onto Modified Chitosan Supports", Appllied Biochemistry and Biotechnology, v.184, pp.182-196, 2018.

[28] TONG, T, LI, Y., HOU, R., et al., "Decoration of chitosan microspheres with Brønsted heteropolyacids and Lewis ion Ti: trifunctional catalysts for esterification to biodiesel", RSC Advances., v. 7, pp. $42422-$ 42429, 2017.

[29] CAIADO, M., CASTANHEIRO, J. E., "Composites chitosan/SBA-15 with sulfonic acid groups as heterogeneous catalysts for biodiesel production, Polymer science: research advances, practical applications and educational aspects", In: A. Mendez-Vilas, A. Solano-Martin Eds., Formatex Research Center, Spain, pp.196-176, 2016.

[30] CHAMIDY, R.H.N., "The Use of Heterogeneous Catalysts of Chitosan Sulfonate Bead on the Esterification Reaction of Oleic Acid and Methanol", In: IOP Conference Series: Materials Science and Engineering,v. 202, pp.1-8, 2017.

[31] BRUGNEROTTO, J., LIZARDI, J., GOYCOOLEA, F. M., et al., “An infrared investigation in relation with chitin and chitosan characterization”, Polymer, v. 42, pp. 3569-3580, 2001.

[32] AL-REMAWI, M. M. A., "Properties of Chitosan Nanoparticles Formed Using Sulfate Anions as Crosslinking Bridges", American Journal of Applied Sciences, v.9, pp. 1091-1100, 2012.

[33] MOGHAdAS, B., DASHTimOGHADAM, E., MIRZADEH, H., et al., "Novel Chitosan-Based Nanobiohybrid Membranes for Wound Dressing Applications”, RSC Advances,v. 6, pp. 7701-7711, 2016.

[34] VARUM, K. M, OTTÙH, M. H, SMIDSRÙD, O., "Acid hydrolysis of chitosans", Carbohydrate Polimers, v.46, pp. 89-98, 2001.

[35] YEN, T. M., YANG, H, J, MAU, L. J., "Physicochemical characterization of chitin and chitosan from crab shells", Carbohydrate Polymers, v.75, pp. 15-21,2009.

[36] SILVA, M.C, FIDELES, T.B., FOOK, M.V.L., "Esferas de quitosana e quitosana/curcumina pelo método de gelificação ionotrópica: influência da incorporação do fármaco", Revista Eletrônica de Materiais e Processos, v.10, pp. 21-28, 2015.

[37] LI, X., XIE, H., LIN, J., et al., "Characterization and biodegradation of chitosan-alginate polyelectrolyte complexes”, Polymer Degradation and Stability, v. 94, pp. 1-6, 2009.

[38] NETO, T.G.C., GIACOMETTI, E.A., FERREIRA, C.F., et al., "Thermal Analysis of Chitosan Based Networks", Carbohydrate Polymers, v. 62, pp. 97-103, 2005.

[39] HORN, M. M., MARTINS, A.C.V., PLEPIS, G.D.M.A, "Determinação da energia de ativação em hidrogéis poliméricos a partir de dados termogravimétricos”, Polímeros, v. 20, pp. 201-204, 2010.

[40] ZENG, L. QIN, C., WANG, L., et al., "Volatile compounds formed from the pyrolysis of chitosan", Carbohydrate Polymers, v. 83, pp. 1553-1557, 2011.

[41] HONG, P., LI, S., OU, C., et al., "Thermogravimetric Analysis of Chitosan", Journal Applied Polymer Science, v. 105, pp. 547-551, 2007.

[42] KASAAI, R. M., ARUL, J., CHARLET, G., "Fragmentation of chitosan by acids", The Scientific World Journal, pp. 1-11, 2013.

[43] WITOON, T., CHAREONPANICH, M., LIMTRAKUL, J., "Effect of acidity on the formation of silicachitosan hybrid materials and thermal conductive property", Journal of Sol-Gel Science and Technology, v. 51, pp.146-152, 2009. 
[44] TSAI, H., WANG, Y., LIN, J., et al., "Preparation and properties of sulfopropyl chitosan derivatives with various sulfonation degree", Journal of Applied Polymer Science., v.116, pp.1686-1693, 2010.

[45] SÁDABA, I., GRANADOS, M.L., RIISAGER, A., et al., "Deactivation of solid catalysts in liquid media:the case of leaching of active sites in biomass conversion reactions", Green Chemistry, v. 17, pp.4133$4145,2015$. 